\title{
Improvement of Bioactive Compounds Content and Antioxidant Properties in Crackers with the Incorporation of Prickly Pear and Potato Peels Powder
}

\author{
Yousif Elhassaneen, Sherif Ragab, Raghda Mashal \\ Nutrition and Food Science Department, Faculty of Home Economics, Minoufiya University, Shebin El-Kom, Egypt \\ Email address: \\ yousif12@hotmail.com (Y. Elhassaneen), sherione11@yahoo.com (S. Ragab),mmmraghda@gmail.com (R. Mashal)
}

\section{To cite this article:}

Yousif Elhassaneen, Sherif Ragab, Raghda Mashal. Improvement of Bioactive Compounds Content and Antioxidant Properties in Crackers with the Incorporation of Prickly Pear and Potato Peels Powder. International Journal of Nutrition and Food Sciences. Vol. 5, No. 1, 2016, pp. 53-61. doi: 10.11648/j.ijnfs.20160501.18

\begin{abstract}
Prickly pear peel (PPP) and potatoes peel (PP) are considered as a waste by-products which obtained during processing of prickly pear and potatoes, huge amount of peels are generated, and their disposal is a major problem and causes environmental pollution. In the present study, PPP and PP were dehydrated under vacuum at $70^{\circ} \mathrm{C}$ for 3 hrs to obtain prickly pear peel powder (PPPP) and potatoes peel powder (PPP) with 7\% moisture content. These by-products were phytochemically analyzed, incorporated into crackers at $5 \%$ levels as a potential source of bioactive compounds. Bioactive compounds analysis indicated that PPPP and PPP contains high levels of many valuable bioactive compounds/antioxidants such total phenolics, (421

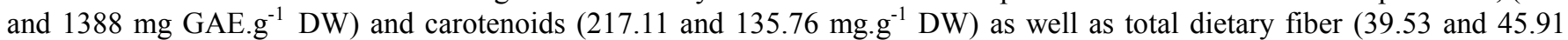
g. $\left.100 \mathrm{~g}^{-1} \mathrm{DW}\right)$. The total dietary fiber, carotenoids and total phenolics content in crackers increased from 5.89, 3.01 and 110.23 to 8.11, 14.34 and 143.28 with 5\% incorporation of PPPP and 8.74 g. $100 \mathrm{~g}^{-1}, 7.88 \mathrm{mg}^{-1} \mathrm{~g}^{-1}$ and 192.79 mg EGA.g ${ }^{-1}$ with $5 \%$ incorporation of PPP, respectively. Also, the antioxidant activity (AA) in control crackers was $30.11 \%$ which increased to 38.14 and $42.07 \%$ with the incorporation of PPPP and PPP by 5\%, respectively. In conclusion, the results suggest that by incorporating PPPP and PPP, it is possible to enhance the nutritional and functional quality (bioactive compounds and antioxidant activity) of crackers without affecting on their sensory characteristics.
\end{abstract}

Keywords: Prickly Pear, Potatoes, Peel, Powder, Dietary Fiber, Antioxidant Activity, Sensory Characteristics

\section{Introduction}

Agricultural and food industries in the Arab world represent a large proportion of waste was estimated at18.14 million tons per year and represent remnants of fruits and vegetables manufacture about $6.14 \%$ of this amount (http://elasaala. blogspot. com/2012/01/blog-post_2703.html). Processing of fruits, vegetables, and oilseeds may results in high amounts of waste materials such as peels, seeds, stones and oilseed meals. Disposal of these materials usually represents a problem that is further aggravated by legal restrictions. Plant waste is prone to microbial spoilage; therefore, drying is necessary before further exploitation. The cost of drying, storage, and transport poses additional economical limitations to waste utilization. Therefore, agro-industrial waste often is utilized as feed or fertilizer. However, demand for feed or fertilizer varies and depends on agricultural production. Moreover, valuable nutrients contained in agro-industrial wastes are lost. Thus new aspects concerning the use of these wastes as by-products for further exploitation on the production of food additives or supplements with high nutritional value have gained increasing interest because these are high-value products and their recovery may be economically attractive. It is well known that agro-industrial by-products are rich in dietary fibers, some of which contain appreciable amounts of colorants, antioxidant compounds or other substances with positive health effects, while some of them, like the oilseed meals, are rich in proteins [1]. Some major source of food wastes are potatoes and prickly pear, some of the most popular vegetables and fruits.

Potato (Solanum tuberosum L.) is the largest vegetable crop worldwide, amounting to approximately 320 million metric tons annually [2]. Processing of potatoes (mainly for the production of chips, French fries, and dehydrated products) has presented a steady increase during the last decades, 
exceeding considerably the amount of the vegetable consumed as fresh $[1,3,4]$. Solid waste generated during processing consists mostly of potato peels but also contains green, immature, and cull potatoes and amounts to $15-45 \%$ depending on the procedure applied [4]. It is used as animal feed, though fermentation for the production of single cell or alcohol has been considered [5]. Water from potato processing is used for the recovery of proteins by heat coagulation [5]. Recent investigations suggested the use of water extracts from potato processing waste for the recovery of antioxidants [6].

Prickly pear (Opuntia ficus-indica), commonly known as prickly pear, belongs to the family Cactaceae. Being so water-use efficient, they are highly useful in arid and semiarid environments, particularly during prolonged dry spells or failure of the monsoon [7]. So, it is widely distributed in Latin America, South Africa and the Mediterranean area including Egypt, [8]. It has been used in traditional folk medicine because of its role in treating a number of diseases and conditions, including anti-inflammatory effects [9], hypoglycemic effects [10], inhibition of stomach ulceration [11], neuroprotective effects [12]. Through antioxidant actions and also used for treating diabetes, hypertension, burns, bronchial, asthma edema, and indigestion in many countries over the world [13-14]. One of the most frequently utilized fruit and vegetable technologies is juice production. Juices, in general, are a good source of sugars, vitamins and minerals all valuable components to human health. In addition to their nutritional and medicinal properties, these plants contain compounds which have several commercial applications. In addition, the phenolic constituents of peels prickly pear cactus were isolated and identified using different chromatographic techniques [15]. Studies aims to magnify the using of prickly pear peel in food and nutritional applications are still a dearth, and more research is required.

Snack, defined as a light meal eaten between regular meals include a broad range of products that can take many forms. Definitions of snacks are being modified to include sandwiches, yogurt and even ice creams. Among snacks, crackers are the most popularly consumed bakery items parts of the world. Some of the reasons for such wide popularity are their ready to eat nature, affordable cost, good nutritional quality, availability in different tastes and longer shelf life [16]. Reported was available on the use of oat bran, wheat bran, rice bran as a source of dietary fiber content in bread and other bakery products [17-19]. Recently, Sudha et al., [20] reported that influence of different cereal brans on sensory quality of biscuits. On the other hand, fruit dietary fiber concentrates have better nutritional quality than those found in cereals due to higher proportion of soluble dietary fiber (SDF) and significant content of dietary fiber associated bioactive compounds [21-22].

In Egypt, the bakery industry has grown tremendously over the recent years. Such as reported by Elhassaneen et al., [23] and Ahmed, [24], bakery products are varied by addition of value added ingredients. Among the added ingredients, dietary fiber and phytochemicals have gained tremendous attention [25-26]. Several years ago, many studies reported the improvement in nutritional and functional properties of cookies and bread with the incorporation of flour with plant by-products powder $[1,4,23,26]$. Although, there is an increasing demand for high fiber and phytochemicals ingredients in food products including snacks. Therefore, the objective of this work is to analyze some plant by-products including potatoes and prickly peach peels that constitute to waste for their nutraceutical values as food ingredient thus reducing its contribution to environmental pollution. Also, utilization of such by-products for their recovery of dietary fibers, bioactive compounds and antioxidants in the production of snacks such crackers will be in the scope of this study.

\section{Materials and Methods}

\subsection{Materials}

\subsubsection{Wheat Flour}

Variety Giza 155 wheat (Triticum vulgare) was obtained from Shebin El-Kom market, Minoufiya Governorate, Egypt during the 2013 harvesting period. The collected samples was transported to the laboratory and stored immediately on the refrigerator at $0^{\circ} \mathrm{C}$ until using in preparation of flour. For flour preparation, the kernels was milled by using of laboratory mill (El-Araby, Benha, Egypt) and sieved through 60 and 50 meshes screen to obtain wheat flour extraction rate 72 .

\subsubsection{Food by-Products}

Potato peel (Solanum tuberosum L.) was obtained from SFCO For Manufacturing \& Export Agricultural Products, El Negila, Kom Hamada, Behira Government, Egypt; and prickly pear fruits (Opuntia ficus-indica), used for prickly pear peel preparation were obtained from the local markets of Tanta City, Egypt.

\subsubsection{Crackers Ingredients}

Salt, bicarbonate soda, yeast and shortening were purchased from the local markets of Shebin El-Kom City, Egypt.

\subsection{Methods}

\subsubsection{Preparation of Food by-Products Peel Powder}

(i). Prickly pear peel powder (PPPP): Unripe prickly pear pulp and unripe prickly pear peel were soaked in $0.1 \%$ sodium metabisulphite solution for $30 \mathrm{~min}$, washed, sliced and dried at $60^{\circ} \mathrm{C}$ for 24 hours in hot air oven (AFOS Mini Smoker, England). This is followed by milling with grinder (Retsch Micro Universal Bench Top Grinder, Germany) to produce the respective flour types.

(ii). Potato peel powder (PPP): Potato peels were washed and then dried in a hot air oven (Horizontal Forced Air Drier, Proctor and Schwartz Inc., Philadelphia, PA) at $55^{\circ} \mathrm{C}$. The dried peels were ground into a fine powder in high mixer speed (Moulinex Egypt, El-Araby Co., Egypt). The material that passed through an 80 mesh sieve was retained for use. 


\subsubsection{Preparation of Crackers}

The crackers were prepared according to the modified method of Manley, [27]. Formulation of the crackers is applied as follow: wheat flour, $100 \mathrm{~g}$; shortening, $9.64 \mathrm{~g}$; salt, $2.02 \mathrm{~g}$; sodium bicarbonate, $0.16 \mathrm{~g}$; yeast, $3.48 \mathrm{~g}$ and water 50 g. Yeast was mixed with water $\left(25^{\circ} \mathrm{C}\right)$ to form a suspension, to which the other ingredients were then added and kneaded to form smooth dough. Substitution of wheat flour with prickly pear peel powder (PPPP) and potato peel powder (PPP) were conducted based on $5 \%$ of the weight of the wheat flour. The dough was later proofed for 2 hours in a proofer (Bakbar E81, New Zealand), followed by sheeting to $1.0 \mathrm{~mm}$ thickness using a dough sheeter (Esmach, Italy). The dough was then cut into squares measuring $3 \mathrm{~cm} \times 3 \mathrm{~cm}$ and 'docked' prior to baking at $170^{\circ} \mathrm{C}$ for $15 \mathrm{~min}$.

\subsubsection{Determination of Total Phenolics, Carotenoids, Total Dietary Fiber and Antioxidant Activity}

Total phenolics, carotenoids and total dietary fiber in selected by-products and cracker samples were analyzed as follow: By-products and cracker samples were extracted with $80 \%$ acetone and centrifuged at $10,000 \mathrm{~g}$ for $15 \mathrm{~min}$. For cracker samples, one gram of biscuit powder was extracted with $20 \mathrm{ml}$ of $80 \%$ acetone and centrifuged at $8000 \mathrm{~g}$ at room temperature. The supernatant obtained from both samples were used for the analysis of total phenolics, carotenoids and antioxidant activity.

Total phenolics were determined using Folin-Ciocalteu reagent [28]. Two hundred milligrams of sample was extracted for $2 \mathrm{~h}$ with $2 \mathrm{~mL}$ of $80 \% \mathrm{MeOH}$ containing $1 \%$ hydrochloric acid at room temperature on an orbital shaker set at $200 \mathrm{rpm}$. The mixture was centrifuged at $1000 \mathrm{~g}$ for $15 \mathrm{~min}$ and the supernatant decanted into $4 \mathrm{~mL}$ vials. The pellets were combined and used for total phenolics assay. One hundred microliters of extract was mixed with $0.75 \mathrm{~mL}$ of Folin-Ciocalteu reagent (previously diluted 10-fold with distilled water) and allowed to stand at $22^{\circ} \mathrm{C}$ for $5 \mathrm{~min} ; 0.75$ $\mathrm{ml}$ of sodium bicarbonate $\left(60 \mathrm{~g} . \mathrm{L}^{-1}\right)$ solution was added to the mixture after $90 \mathrm{~min}$ at $22^{\circ} \mathrm{C}$, absorbance was measured at 725 $\mathrm{nm}$. Results are expressed as gallic acid and equivalents. The total carotenoids in $80 \%$ acetone extract were determined by using the method reported by Litchenthaler, [29]. Total dietary fiber content in the MPP was estimated according to the method described by Asp et al., [30].

Antioxidant activity of tested spices extracts and standards ( $\alpha$-tocopherol and BHT; Sigma Chemical Co., St. Louis, Mo) was determined according to the $\beta$-carotene bleaching method following a modification of the procedure described by Marco, [31]. For a typical assay, $1 \mathrm{~mL}$ of $\beta$-carotene (Sigma) solution, $0.2 \mathrm{mg} / \mathrm{mL}$ in chloroform, was added to round-bottom flasks $(50 \mathrm{~mL})$ containing $0.02 \mathrm{~mL}$ of linoleic acid (J.T. Baker Chemical Co., Phillipsburg, NJ) and $0.2 \mathrm{~mL}$ of Tween 20 (BDH Chemical Co., Toronto, On). Each mixture was then dosed with $0.2 \mathrm{~mL}$ of $80 \% \mathrm{MeOH}$ (as control) or corresponding plant extract or standard. After evaporation to dryness under vacuum at room temperature, oxygenated distilled water $(50 \mathrm{ml})$ was added and the mixture was shaken to form a liposome solution. The samples were then subjected to thermal auto-oxidation at $50^{\circ} \mathrm{C}$ for $2 \mathrm{~h}$. The absorbance of the solution at $470 \mathrm{~nm}$ was monitored on a spectrophotometer (Beckman DU-50) by taking measurements at $10 \mathrm{~min}$ intervals, and the rate of bleaching of $\beta$-carotene was calculated by fitting linear regression to data over time. All samples were assayed in triplicate. Various concentrations of BHT, BHA, and $\alpha$-tocopherol in $80 \%$ methanol was used as the control. Antioxidant activity was calculated in four different ways. In the first, absorbance was plotted against time, as a knit curve, and the absolute value of slope was expressed as antioxidant value (AOX). Antioxidant activity (AA) was all calculated as percent inhibition relative to control using the equation (1) [32].

$$
\mathrm{AA}=\left(\mathrm{R}_{\text {control }}-\mathrm{R}_{\text {sample }}\right) / \mathrm{R}_{\text {control }} \times 100
$$

Where: $\mathrm{R}$ control and $\mathrm{R}$ sample were the bleaching rates of $\beta$-carotene in reactant mixture without antioxidant and with plant extract, respectively.

The third method of expression based on the oxidation rate ratio (ORR) was calculated according to the method of Marinova et al., [33] using the equation (2):

$$
\mathrm{ORR}=\mathrm{R}_{\text {sample }} / \mathrm{R}_{\text {control }}
$$

Where: $\mathrm{R}_{\text {control }}$ and $\mathrm{R}_{\text {sample }}$ are the same in the previous equation.

In the fourth method, the antioxidant activity coefficient (AAC) was calculated as described by Mallet et al., equation (3) [34].

$$
\left.\mathrm{AAC}=\left(\mathrm{Abs}_{\mathrm{S} 120}-\mathrm{Abs}_{\mathrm{C} 120}\right) / \mathrm{Abs}_{\mathrm{C} 0}-\mathrm{Abs}_{\mathrm{C} 120}\right) \times 100
$$

Where: Abs S 120 was the absorbance of the antioxidant mixture at time $120 \mathrm{~min}, \mathrm{Abs}_{\mathrm{C} 120}$ was the absorbance of the control at time $120 \mathrm{~min}$, Abs $\mathrm{C}_{0}$ was the absorbance of the control at zero time.

\subsubsection{Sensory Evaluation}

Sensory evaluation was carried out with 14 panelists comprising of postgraduate students from Minoufiya University, Shebin El-Kom, Egypt. Testing was done in the sensory laboratory. Each panelist was served with 5 randomly arranged cracker samples on a rectangular plastic tray. The crackers were individually sealed in a pouch and coded with a three-digit number prior to testing. The 5 samples consisted of two types of composite flour crackers and a control (100\% wheat flour). Water was provided for rinsing between the samples. Panelists were required to evaluate the colour, crispiness, taste and overall acceptance of the crackers using the 9-point hedonic scale with $1=$ dislike extremely, $2=$ dislike very much, $3=$ dislike moderately, $4=$ dislike slightly, $5=$ neither like nor dislike, $6=$ like slightly, $7=$ like moderately, $8=$ like very much, and $9=$ like extremely.

\subsubsection{Statistical Analysis}

All measurements were done in triplicate and recorded as mean \pm SD. Statistical analysis was performed with the Student $t$-test and MINITAB 12 computer program (Minitab Inc., State College, PA). 


\section{Results and Discussion}

\subsection{Analysis of Selected Food by-Products}

\subsubsection{Total Dietary Fiber, Carotenoids and Phenolics Contents}

Total dietary fiber, carotenoids and phenolics contents of selected food by-products are shown in Table (1). The data showed that the total dietary fiber content was ranged 39.53 and $45.91 \mathrm{~g} .100 \mathrm{~g}^{-1}$, total carotenoids was 217.11 and 135.76 mg. $100 \mathrm{~g}^{-1}$ and total phenolics was 421 and $1388 \mathrm{mg}$ GAE. $100 \mathrm{~g}^{-1}$ for PPPP and PPP, respectively. The PPP was recorded the highest content of total dietary fiber and total phenolics while PPPP recorded the highest values of total carotenoids. In similar study of Ahmed, [26] found that the total dietary fiber content of ROSP, MPP, CLP and PPP were ranged $27.15-42.71 \mathrm{~g} .100 \mathrm{~g}^{-1}$, total carotenoids was 92.43-412.14 mg.100 $\mathrm{g}^{-1}$ and total phenolics was 1104-7129 mg EGA.100 $\mathrm{g}^{-1}$. Such data confirmed that such tested by-product could be played a significant role in nutritional/pharmaceutical applications through their high content of bioactive compounds. Such as reviewed in Al-Weshahy and Rao, [35] dietary fiber is well known as a bulking agent, increasing the intestinal mobility and hydration of the feces. Several authors have reviewed the importance of consumption of moderate amounts of dietary fibers for human health [36-37]. Scientifically speaking, dietary fiber is a broad term that includes several carbohydrates; cellulose, hemicelluloses, lignins, pectins, gums etc. [38]. Camire et al., [39] reported that PP fibers are primarily insoluble, and can bind bile acids in-vitro. It is believed that binding of bile acids is one of the mechanisms whereby certain sources of dietary fibers lower plasma cholesterol. Lazarov and Werman, [40] studied the hypocholesterolemic effect of dietary fiber from
PP and found that after four weeks of feeding on potato peels, rats showed $40 \%$ reduction in plasma cholesterol content and $30 \%$ of hepatic fat cholesterol levels were reduced as compared with animals fed only with cellulose supplemented diet. Defects of dietary fiber on lipid-profile influence several health related issues. High concentrations of low-density lipoprotein (LDL) cholesterol, other dyslipidemia [high concentration of triglycerides and low concentration of high-density lipoprotein (HDL) cholesterol], leads to blood platelets aggregation [41], risk factors for cardiovascular diseases (CVD) [42], and hypertension [43]. Moreover, high intake of dietary fibers has a positive influence on blood glucose profile and it is related health complications, in healthy and diabetic individuals of both types. By altering the gastric emptying time, dietary fibers are able to affect the absorption of other simple sugars. The effect of dietary fibers on blood glucose and insulin response has been demonstrated by many other authors as well [35, 44]. Recently, Shalaby [25] reported that adding the food by-products such onion skin powder (high level of dietary fiber and phenolic compounds) to the ground meats before the grilling process and used in feeding of rats leads to decline in their serum glucose and lipid oxidation and improve in the liver functions.

Table 1. Total dietary fiber, carotenoids and phenolics contents of selected food by-products

\begin{tabular}{lll}
\hline Parameters & $\begin{array}{l}\text { Prickly pear peel } \\
\text { powder (PPPP) }\end{array}$ & $\begin{array}{l}\text { Potato peel } \\
\text { powder (PPP) }\end{array}$ \\
\hline Total dietary fiber $\left(\mathrm{g} .100 \mathrm{~g}^{-1}\right)$ & $39.53 \pm 3.50$ & $45.91 \pm 3.83$ \\
Total carotenoids $\left(\mathrm{mg} .100 \mathrm{~g}^{-1}\right)$ & $217.11 \pm 20.44$ & $135.76 \pm 10.42$ \\
Total phenolics $\left(\mathrm{mg} \mathrm{EGA.} 100 \mathrm{~g}^{-1}\right)$ & $421 \pm 64$ & $1388 \pm 98$ \\
\hline
\end{tabular}

${ }^{\mathrm{e}}$ Each value represents the mean of three replicates $\pm \mathrm{SD}$.

Table 2. Antioxidant activity of selected food by-products

\begin{tabular}{|c|c|c|c|c|}
\hline Samples & $\begin{array}{l}\text { Antioxidant value }{ }^{\mathrm{a}} \\
\operatorname{AOX}(\mathrm{A} / \mathrm{h})\end{array}$ & $\begin{array}{l}\text { Antioxidant activity } \\
\text { AA }(\%)\end{array}$ & $\begin{array}{l}\text { Oxidation rate ratio } \\
\text { (ORR) }\end{array}$ & $\begin{array}{l}\text { Antioxidant activity coefficient } \\
\text { (AAC) }\end{array}$ \\
\hline Prickly pear peel powder (PPP) & $0.164 \pm 0.021^{\mathrm{a}^{*}}$ & $71.05 \pm 5.11^{\mathrm{c}}$ & $0.289 \pm 0.020^{\mathrm{a}}$ & $407.48 \pm 43.85^{\mathrm{c}}$ \\
\hline Potatoes peel powder (PPP) & $0.095 \pm 0.011^{\mathrm{b}}$ & $83.22 \pm 2.12^{\mathrm{b}}$ & $0.167 \pm 0.011^{\mathrm{b}}$ & $619.06 \pm 50.87^{b}$ \\
\hline Control & $0.565 \pm 0.031$ & $0.00 \pm 0.00$ & $0.998 \pm 0.125$ & $0.00 \pm 0.00$ \\
\hline BHT, 50 mg/L & $0.079 \pm 0.012^{b}$ & $86.03 \pm 10.34^{b}$ & $0.139 \pm 0.013^{\mathrm{c}}$ & $667.91 \pm 69.90^{\mathrm{b}}$ \\
\hline$\alpha$-tocopherol, $50 \mathrm{mg} / \mathrm{L}$ & $0.011 \pm 0.006^{c}$ & $97.99 \pm 9.43^{\mathrm{a}}$ & $0.020 \pm 0.007^{\mathrm{d}}$ & $875.83 \pm 100.65^{\mathrm{a}}$ \\
\hline
\end{tabular}

${ }^{\mathrm{a}}$ Antioxidant value $(\mathrm{AOX}, \mathrm{A} / \mathrm{h})=$ The absolute value of slope (Abs was plotted against time).

${ }^{\mathrm{b}}$ Antioxidant activity $(\mathrm{AA}, \%)=(\mathrm{R}$ control - $\mathrm{R}$ sample $) / \mathrm{R}$ control $\mathrm{x} 100$ where: $\mathrm{R}$ control and $\mathrm{R}$ sample were the bleaching rates of beta-carotene in reactant mixture without antioxidant and with plant extract, respectively.

${ }^{\mathrm{c}}$ Oxidation rate ratio $(\mathrm{ORR})=\mathrm{R}$ sample $/ \mathrm{R}$ control.

${ }^{\mathrm{d}}$ Antioxidant activity coefficient $(\mathrm{AAC})=($ Abs S 120 - Abs C 120) / Abs C 0 - Abs C 120) x 1000 where: Abs S 120 was the absorbance of the antioxidant mixture at time $120 \mathrm{~min}$, Abs C 120 was the absorbance of the control at time $120 \mathrm{~min}, \mathrm{Abs} \mathrm{C} 0$ was the absorbance of the control at zero time.

*Each value represents mean \pm SD. Values with the different letters in the same column are significantly different $\mathrm{P} \leq 0.05$.

Table 3. Total dietary fiber, carotenoids and phenolics contents and antioxidant activity of the control and composite flour crackers

\begin{tabular}{|c|c|c|c|c|}
\hline Treatment & Total dietary fiber $\left(\mathrm{g} .100 \mathrm{~g}^{-1}\right)$ & Total carotenoids $\left(\mathrm{mg}^{100 \mathrm{~g}^{-1}}\right)$ & Total phenolics (mg GAE.100g ${ }^{-1}$ ) & Antioxidant activity, AA (\%) \\
\hline Control crackers $(\mathrm{CC})$ & $5.89 \pm 0.20^{b}$ & $3.01 \pm 0.62^{b}$ & $110.23 \pm 15.34^{c}$ & $30.11 \pm 2.17^{b}$ \\
\hline $\mathrm{CC}+5 \% \mathrm{PPPP}$ & $8.11 \pm 0.32^{\mathrm{a}}$ & $14.34 \pm 1.98^{\mathrm{a}}$ & $143.28 \pm 9.81^{b}$ & $38.14 \pm 1.43^{\mathrm{a}}$ \\
\hline $\mathrm{CC}+5 \% \mathrm{PPP}$ & $8.74 \pm 0.24^{\mathrm{a}}$ & $7.88 \pm 1.21^{\mathrm{b}}$ & $192.79 \pm 21.67^{\mathrm{a}}$ & $42.07 \pm 1.09^{\mathrm{a}}$ \\
\hline
\end{tabular}

${ }^{\mathrm{e}}$ Each value represents the mean of ten replicates $\pm \mathrm{SD}$. Mean values with the different letters in the same column mean significantly different at level $\mathrm{p} \leq 0.05$. 


\subsubsection{Antioxidant Activities}

The antioxidant activities and total phenolics of the tested food by-products are shown in Table (2). From such data it could be noticed that the by-products powder showed considerable differences in antioxidant activity $(\mathrm{AA}=71.05$ $83.22 \%$ ) when it was calculated by the four different methods used in this study. potato peels powder (PPP) showed strong activity because of its high phenolic content (1388 mg EGA. $100 \mathrm{~g}^{-1} \mathrm{DW}$ ) while prickly pear peel powder (PPPP) showed relatively low content in both antioxidant activity and the total phenolics (421 mg EGA.100 $\mathrm{g}^{-1}$ ). The decrease in absorbance of $\beta$-carotene in the presence of different methanolic tested food by-products extracts (and well-known antioxidants used as standards) with the oxidation of $\beta$-carotene and linoleic acid, antioxidant stability, is shown in Figure (1). Such data indicated that PPP recorded the lowest decreasing followed by PPPP. The values of PPP absorbance through $120 \mathrm{~min}$ are coming well i.e. corresponding to the line of $50 \mathrm{mg} . \mathrm{L}^{-1}$ of $\alpha$-tocopherol and upper to the line $50 \mathrm{mg} . \mathrm{L}^{-1}$ of BHT. By the same manner, PPPPis coming close to the line of $50 \mathrm{mg} . \mathrm{L}^{-1}$ of BHT. These data proved the high stability of the all tested food by-products when comparing with that more common standards, BHT and $\alpha$-tocopherol. In a similar study, Ahmed, [24] reported highly antioxidant activity (AA= $84.87-97.66 \%)$ and phenolic content (1679-8946 mg EGA. $\left.100 \mathrm{~g}^{-1} \mathrm{DW}\right)$ for many food by-products including PPP, red onion skin powder (ROSP) and mango peel powder (MPP). The high antioxidant stability (The decrease in absorbance of $\beta$-carotene in the presence of by-product methanolic extracts, and well-known antioxidants used as standards, with the oxidation of $\beta$-carotene and linoleic acid) was recorded for the methanol extract of ROSP followed by MPP and PPP, respectively.

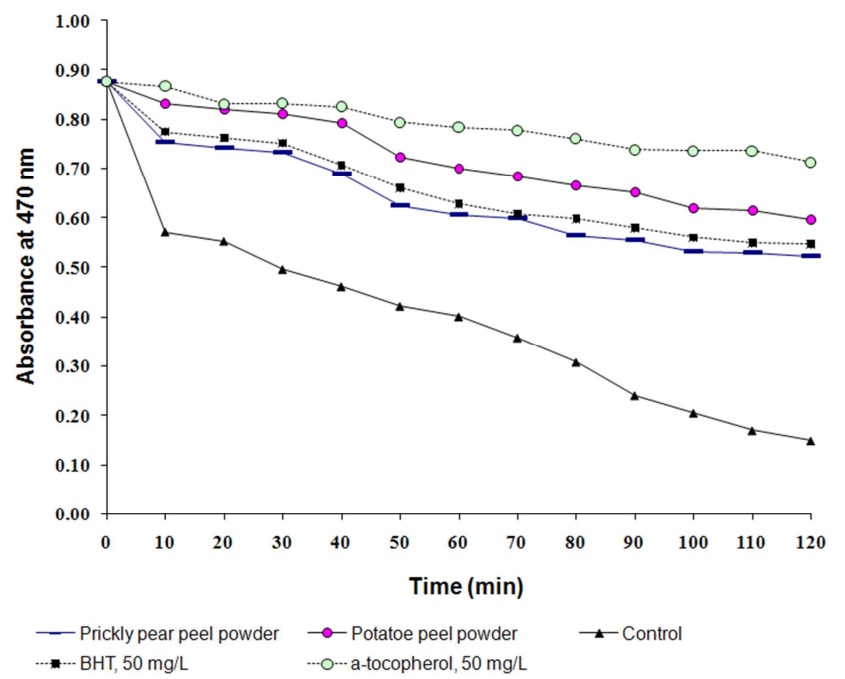

Figure 1. Activity of selected food by-products assayed by the $\beta$-carotene bleaching method (BHT $\alpha$-tocopherol at $50 \mathrm{mg} / \mathrm{L}$ concentration was used as a reference).

In the correlation analysis, important differences were found between phenolics, carotenoids and antioxidant activity of food by-products (Figures 2). When all food by-products were included in the statistical analysis, there was a positive significant $(\mathrm{p} \leq 0.05)$ relationship between total phenolics in PPPP $\left(r^{2}=0.636\right)$, total phenolics in PPP $\left(r^{2}=0.834\right)$, total carotenoids in PPPP $\left(\mathrm{r}^{2}=0.531\right)$, total carotenoids in PPP $\left(\mathrm{r}^{2}=\right.$ $0.593)$ and antioxidant activity. These correlations confirm that phenolic compounds with carotenoids are mainly responsible for the antioxidant activity of the tested by-products. Also, these data indicates that many other bioactive compounds beside phenolics and carotenoids such vitamins, fibers, minerals etc probably contribute in the antioxidant activity of the tested by-products. This information was confirmed by Osuna-Martínez et al., [45] who reported that antioxidant properties, one medicinal plant that has been proposed having interesting antioxidant activity and protective capacities due to the presence of components such as vitamins $\mathrm{C}$ and $\mathrm{E}$, phenolics and other non-nutrient substances is Opuntia ficus indica (L). In a similar study, Ahmed, [24] reported that positive and highly significant relationship between total phenolics and antioxidant activity for different food by-products including ROSP, PPP and MPP. Also, Velioglu et al., [46] reported that the correlation coefficient between total phenolics and antioxidative activities of 28 plant products and by-products, including sunflower seeds, flaxseeds, wheat germ, buckwheat, several fruits, vegetables, and medicinal plants was statistically significant. Recently, Abou-Elella and Ali [14] reported that the antioxidant of the Egyptian Prickly Pear Cactus (Opuntia ficus-Indica) Peel potency showed significant relationship with the total phenolic content.

\subsection{Analysis of Crackers Enriched with Tested Plant by-Products}

\subsubsection{Bioactive Components and Antioxidant Activity of Control and Composite Flour Crackers}

Table (3) shows the bioactive components and antioxidant activity of control and enriched crackers with the tested by-products. The total dietary fiber, carotenoids and phenolics content in crackers increased from 5.89, 3.01 and 110.23 to $8.11,14.34$ and 143.28 with $5 \%$ incorporation of PPPP and 8.74 g. $100 \mathrm{~g}^{-1}, 7.88 \mathrm{mg} . \mathrm{g}^{-1}$ and $192.79 \mathrm{mg}$ EGA.g ${ }^{-1}$ with $5 \%$ incorporation of PPP, respectively. In parallel, the antioxidant activity (AA) in control crackers was $30.11 \%$ which increased to 38.14 and $42.07 \%$ with the incorporation of PPPP and PPP by $5 \%$, respectively. Tested by-products enriched crackers showed strong activity probably due to their high bioactive compounds (carotenoids and phenolics) content.

Many similar studies indicated that big differentiations have been recorded amongst different tested by-products. For example, Onyeneho and Hettiarachchy, [47] reported that the peels from the red potatoes contained more polyphenols than those from the brown-skinned varieties. Furthermore it was shown that the peel and the pulp of the tubers contain nine phenolic acids differed in their concentrations and appeared to be mainly responsible for the strong antioxidant activities of the peel extracts. Ashoush and Gadallah, [48] investigated the 
effect of mango peels powders (MPP) at different replacing levels $(5,10,15$ and $20 \%)$ and mango kernels powders (MKP) at $(20,30,40$ and $50 \%)$ antioxidant properties of biscuits were evaluated. The content of phenolics increased from 3.84 to
$24.37 \mathrm{mg} / \mathrm{g}$ of biscuit incorporated with deferent levels of MPP and MKP. The biscuits incorporated with MPP and MKP exhibited an improvement in their antioxidant properties.

d
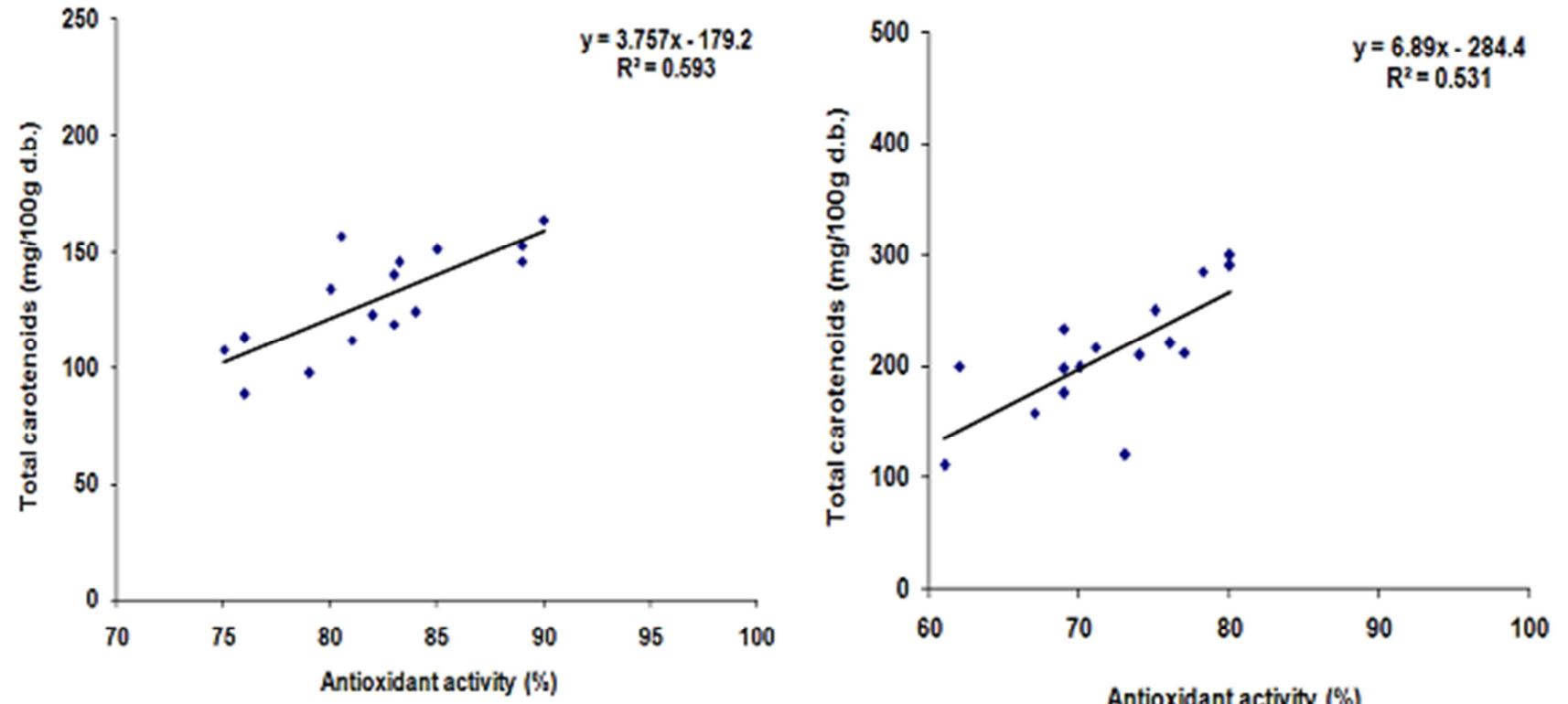

b

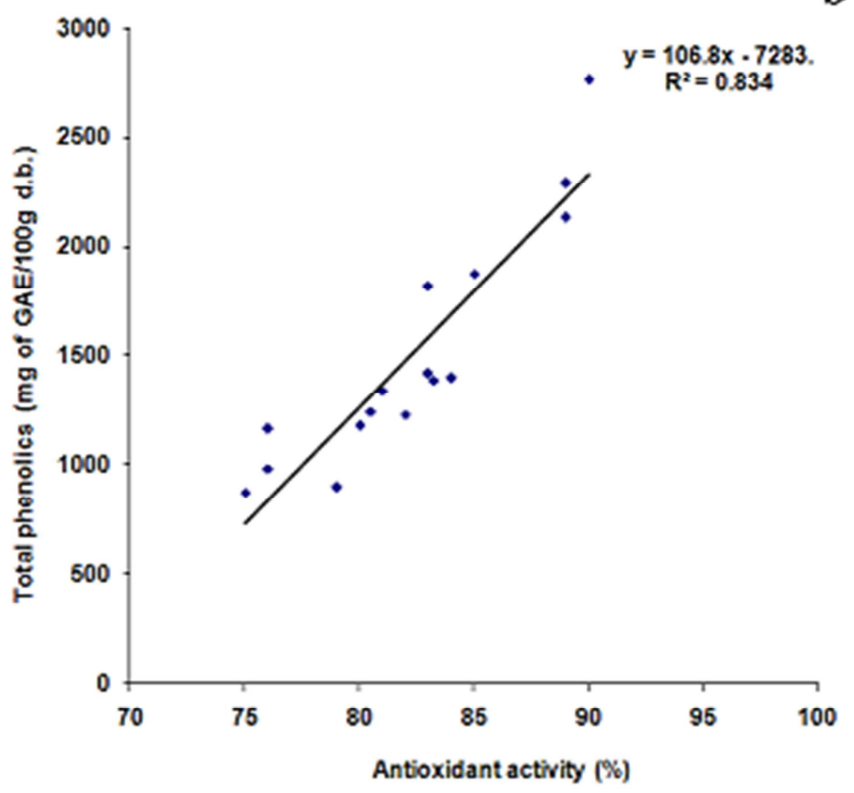

Antioxidant activity $(\%)$

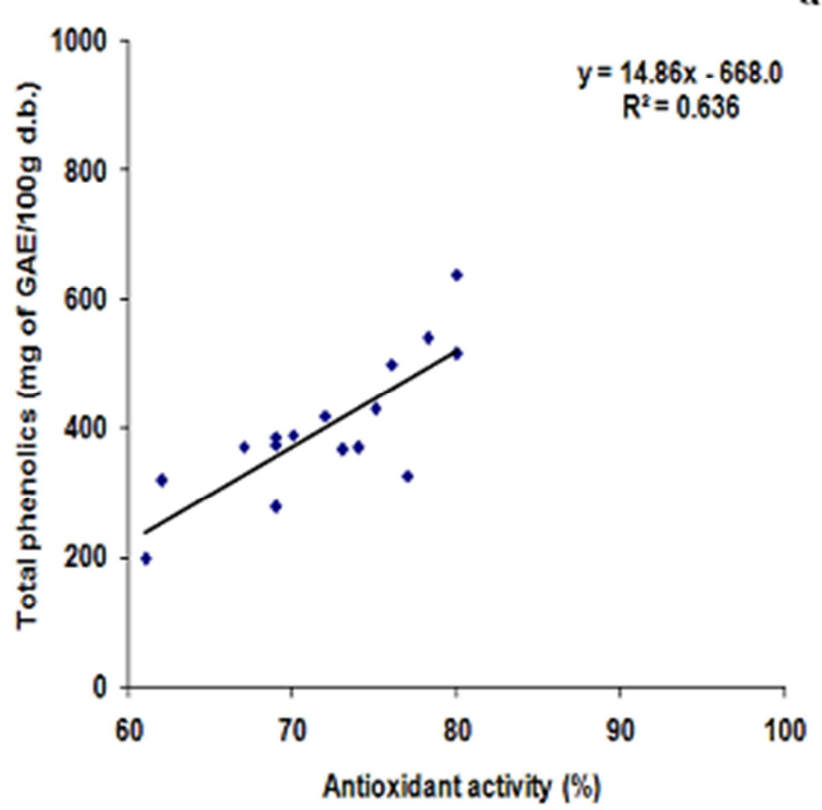

Figure 2. Correlation between bioactive components detected and antioxidant activity (AA) of both food by-products: (a) AA vs. total phenolics in PPPP, (b) AA vs. total phenolics in PPP, (c) AA vs. total carotenoids in PPPP, and (d) AA vs. total carotenoids in PPP.

Also, El-Sadany, [49] found that the mean of phenolic acids content was $2439.21 \pm 113.8 \mathrm{mg} / 100 \mathrm{~g}$ extract of potato peel. Recently, Ahmed [26] indicated that breads formulated with food by-products (PPP, CLP, ROSP and MPP) exhibited increased total dietary fiber (TDF) content. The TDF content in control breads was $6.98 \mathrm{~g} .100 \mathrm{~g}^{-1}$ which increased to 8.22 , $8.72,8.37$ and 9.14 g. $100 \mathrm{~g}^{-1}$ with the incorporation of PPP, CLP, ROSP and MPP by 5\%. The total carotenoids content in control breads was $2.56 \mathrm{mg} . \mathrm{g}^{-1}$ which increased to $8.90,10.02$,
7.01 and $22.04 \mathrm{mg} . \mathrm{g}^{-1}$ with the incorporation of PPP, CLP, ROSP and MPP by 5\%.The total phenolics content in control biscuits was $1.33 \mathrm{mg} . \mathrm{g}^{-1}$ which increased to $103.86,56.12$, 349.43 and $298.05 \mathrm{mg}$ EGA. $\mathrm{g}^{-1}$ with the incorporation of PPP, CLP, ROSP and MPP by $5 \%$. Also, many studies carried out by Hegazy, [50], and Ahmed [26] indicated that there was a positive and significant $(\mathrm{p}<0.01)$ relationship between total phenolics and antioxidant activity in different plant parts. Plant-based foods generally are considered important sources 
of antioxidants in the diet. Antioxidants help protect cells from the potentially damaging physiological process known as "oxidative stress" (damage to healthy cells or DNA by unpaired electrons known as free radicals). Oxidative stress is thought to be associated with the development of chronic diseases including cancer, heart disease, conditions of ageing including neurodegenerative diseases such as Parkinson's and Alzheimer's disease. There are a variety of plant antioxidants with different chemical structures. There are the antioxidant nutrients such as vitamins $\mathrm{C}, \mathrm{E}, \beta$-carotene and the trace element selenium (found in MPP) for which there are Dietary Reference Values (DRVs). However, there are thousands of other bioactive compounds in foods that have antioxidant activity but are not classified as "nutrients." These "non-nutrient antioxidants" include phenolic compounds such as found in PPPP and PPP [51].

\subsubsection{Sensory Evaluation}

Results of sensory evaluation in terms of colour, crunchiness, taste and overall acceptance are presented in Table (4). The PPPP and PPP crackers were significantly different $(p \leq 0.05)$ in colour. The PPP crackers were shown to be the least liked by the panelists. It is reported by Broyart, [52] that the initial acceptance of baked products is much influenced by colour, which can also be an indicator of baking completion. As PPP flour imparts a dark brown colour to the crackers, this might have given the panelists an impression of 'over-baked' product, thus affecting their likings. For colour, among the tested food by-products, the colour of PPPP crackers was rated the highest (7.79) by the panelists. The desirable colour of crackers is mainly due to the Millard browning during baking. However, in PPPP crackers, the colour could be partially contributed by the carotenoid in PPPP flour which imparts a yellowish colour to the crackers. Similar findings were reported in a study by Brennan et al., [53] who observed that an increased flour and thus muffin visual lightness (with more yellowness and brownness rather than dark and yellow green) yield a higher aroma, texture and colour acceptability scores. Colour was not significantly different $(p \leq 0.05)$ between the control and PPPP crackers. Crispiness is perceived when food is chewed between molars, and is usually expressed in terms of hardness and fracturability. In this study, there was no significant difference $(\mathrm{p} \leq 0.05)$ in crispiness amongst the different samples with different composite flour cracker types. This observation could be due to the small percentage of wheat flour substitution in the crackers formulation, which did not affect the gluten network in the dough nor the development of an open internal structure upon baking.

In similar study, Sudha et al., [20] reported that in biscuits prepared from different cereal fiber and found to be crispy at incorporation level of $40 \%$ oat bran, with a very small increase in hardness. No significant difference $(\mathrm{p} \leq 0.05)$ was observed in terms of taste between the control and PPPP crackers. This could probably be due to the nature of PPPP which did not impart any additional flavour to the crackers. However, PPPP was significantly different $(\mathrm{p} \leq 0.05)$ in taste as compared to the control and PPP crackers. The lowest score for the PPP crackers could be attributed to the 'potatony' after-taste, as commented by some of the panelists. There was no significant difference $(\mathrm{p} \leq 0.05)$ in term of overall acceptability among the control and PPPP. This could be attributed to the close resemblance of the cracker types in terms of the colour, crispiness and taste of the commercial crackers in the market. However, the PPP crackers were significantly different $(p \leq 0.05)$ in overall acceptance. The lower ratings for the PPP crackers could be due to the unpleasant taste of the crackers. In similar study of Ashoush and Gadallah, [48] investigated the effect of mango peels powders (MPP) at different replacing levels $(5,10,15$ and 20\%) and mango kernels powders (MKP) at $(20,30,40$ and $50 \%)$ on sensory properties of biscuits were evaluated. Acceptable biscuits with mango flavor were obtained by incorporating up to 10\% MPP and with MKP up to $40 \%$. Recently, Ahmed [26] acceptable breads with MPP and CLP were obtained by incorporating up to $5 \%$. . Wheat flour was also substituted with PP in the production of white bread, but it increased crumb darkening and reduced the loaf volume [54]. Also, Orr et al., [55] found that PP caused a musty odor in breads, but the extrusion of potato peel before its utilization can diminish this aroma from the final product. Additionally, Abdel-Magied, [56] mentioned the effect of using PP in biscuit processing. The resulted biscuits produced using 5 and $10 \%(\mathrm{w} / \mathrm{w})$ of PP replaced wheat flour were smaller in terms of their stack weight and sensory score (color and appearance) in proportion to the levels used. In addition, supplementary biscuits were harder to bite than control biscuits.

Table 4. Sensory evaluation (Scores) of the control and composite flour crackers

\begin{tabular}{lllll}
\hline Treatment & Colour & Crunchiness & Taste & Overall acceptance \\
\hline Control crackers (CC) & $8.33 \pm 0.21^{\mathrm{a}}$ & $8.01 \pm 0.20^{\mathrm{a}}$ & $7.82 \pm 0.14^{\mathrm{a}}$ & $8.22 \pm 0.10^{\mathrm{a}}$ \\
CC $+5 \%$ PPPP & $7.79 \pm 0.17^{\mathrm{b}}$ & $7.23 \pm 0.14^{\mathrm{a}}$ & $7.09 \pm 0.32^{\mathrm{a}}$ & $7.81 \pm 0.29^{\mathrm{a}}$ \\
CC $+5 \%$ PPP & $6.51 \pm 0.23^{\mathrm{c}}$ & $6.51 \pm 0.20^{\mathrm{a}}$ & $6.01 \pm 0.19^{\mathrm{b}}$ & $5.99 \pm 0.15^{\mathrm{b}}$ \\
\hline
\end{tabular}

${ }^{\mathrm{e}}$ Each value represents the mean of ten replicates $\pm \mathrm{SD}$. Mean values with the different letters in the same column mean significantly different at level $\mathrm{p} \leq 0.05$.

\section{Conclusion}

The chemical composition of PPPP and PPP showed that they are a good source of dietary fibers and bioactive compounds such as carotenoids and phenolics. Crackers samples enriched with that by-products showed higher TDF, carotenoids and total phenolics content than the control samples. Increasing of such bioactive compounds in PPPP and PPP incorporated crackers exhibited improving of their antioxidant activity subsequently their properties as functional foods. The tested by-products incorporated crackers by $5 \%$ doesn't affect on their overall quality. 


\section{Acknowledgements}

The financial support of Research Supporting Fund, Minoufiya University, Shebin El-Kom, Egypt is gratefully acknowledged. Sincere thanks are also extended to Dr. Zeinab Eissa for by-products samples preparation and lab assistance.

\section{References}

[1] Vasso, O. and Constantina, T. (2007). Utilization of Plant By-Products for the Recovery of Proteins, Dietary Fibers, Antioxidants, and Colorants. In: Utilization of By-Products and Treatment of Waste in the Food Industry. Ed. By: Vasso Oreopoulou and Winfried Russ. Springer ScienceBusiness Media, LLC, PP. 209-232.

[2] FAO, (2005). Statistical Database at http://apps.fao.org. Agriculture data: Agricultural production-Crops Primary.

[3] Kadam, S.; Natu, R.; Mazza, G. and Jadhav, S. (1991). Waste utilization. In: Salunkhe DK, Jadhav SJ, editors. Potato: production, processing, and products: CRC Press, Boca Raton, USA, PP. 175-199.

[4] Schieber, A.; Stintzing, F. and Carle, R. (2001). By-products of plant food processing as a source of functional compounds-recent developments. Trends in Food Science and Technology, 12(11): 401-413.

[5] Natu, R.; Mazza, G.; Jadhav, S. and Waste, U. (1991). In: Salunkhe DK, Kadam SS, Jadhav SJ, editors. Potato: production, processing, and products: CRC Press, Boca Raton, U. S. A. 175-199.

[6] Rodriguez De Sotillo, D.; Hadley, M. and Holm, E. (1994). Potato peel waste: stability and antioxidant activity of a freeze-dried extract. Journal of Food Science, 59: 1031-1033.

[7] Sing, G. (2003). General Review of Opuntias in India. Journal of the Professional Association for Cactus Development.

[8] Hassan, A. (2011). The effect of phytochemicals on prevention and/or treatment of liver cancer induced by some food pollutants. Ph. D. Thesis, Faculty of Home Economics, Minoufiya University, Shebin El-Kom, Egypt.

[9] Park, E.; Kahng, J. and Paek, E. (1998). Studies on the pharmacological actions of cactus: identification of is anti-inflammatory effect. Arch. Pharm. Res, 21: 30-34.

[10] Frati, A.; Gordillo, B.; Altamirano, P.; Ariza, R.; Cortes-Franco, R. and Chavez, N. (1990). Acute hypoglycemic effect of Opuntia steptacantha Lemaire in NIDDM. Diabetes Care, 13: 455-456.

[11] Galati, E.; Mondello, M.; Giufferida, D.; Dugo, G.; Miceli, N.; Pergolizzi, S. and Taviano, M. (2003). Chemical characterization and biological effects of Sicilian Opuntia ficus indica (L.) Mill. Fruit juice: antioxidant and antiulcerogenic activity. J. Agric. Food Chem., 51: 4903-4908.

[12] Dok-Go, H.; Lee, K.; Kim, H.; Lee, E.; Song, J.; Lee, Y. and Jin C. (2003). Neuroprotective effects of antioxidative flavonoid, quercetin, (1) dihydroquercetin and quercetin 3-methyl ether, isolated from Opuntia ficus indicavar. saboten. Brain Research, 965: 130-136.
[13] Cardador-Martínez, A.; Jiménez-Martínez, C. and Sandoval, G. (2011). Revalorization of cactus pear (Opuntia spp.) wastes as a source of antioxidants. Ciê e Tecn. Alim, 31: 782-788.

[14] Abou-Elella, F. and Ali, R. (2014). Antioxidant and Anticancer Activities of Different Constituents Extracted from Egyptian Prickly Pear Cactus (Opuntia ficus Indica) Peel. Biochem Anal Biochem, 3: 158.

[15] Huseain, A. E. (2013). Technological studies on some vegetables and fruits peels and their utilization on rasing the nutritional values of child foods" $\mathrm{Ph}$. D. Thesis in Nutrition and Food Science, Faculty of Home Economics, Minoufiya University, Egypt.

[16] Gandhi, A.; Kotawaliwale, N.; Kawalkar, J.; Srivastava, D.; Parihar, V. and Raghu, P. (2001). Effect of incorporation of defatted soy flour on the quality of sweet biscuits. Journal of Food Science and Technology, 38(5): 502-503.

[17] Laurikainen, T.; Harkonen, H.; Autio, K. and Poutanen, K. (1998). Effects of enzymes in fiber-enriched baking. J. Sci. Food Agr, 76: 239-249.

[18] Leelavathi, K. and HaridasRao, P. (1993). Development of high fiber biscuits using wheat bran. Journal of Food Science and Technology, 30(3): 187-191.

[19] Saunders, R. (1990). The properties of rice bran as foodstuff. Cereal Foods World, 35(7): 632-634.

[20] Sudha, M.; Vetrimani, R. and Leelavathi, K. (2007). Influence of fibre from different cereals on the rheological characteristics of wheat flour dough and on biscuit quality. Food Chemistry, 100 (4): 1365-1370.

[21] Grigelmo-Miguel, N. and Martin-Belloso, O. (1999). Comparison of dietary fiber from by-products of processing fruits and greens and from cereals. Lebensmittel-WissenschaftFood Science and Technology, 32(8): 503-508.

[22] Chau, C. and Huang, Y. (2003). Comparison of the chemical composition and physicochemical properties of different fibers prepared from the peel of Citrus sinensis L. Cv. Liucheng. Journal of Agricultural and Food Chemistry, 51 (9): 2615-2618.

[23] Elhassaneen, Y.; Sherif, R.; Alaa, E. and Abeer, E. (2013). Mango peel powder: A potential source of phenolics, carotenoids and dietary fiber in Biscuits preparations $2^{\text {nd }}$ International-16th Arab Conference of Home Economics "Home Economics in the Service of Industry"10-11 September, Faculty of Home Economics, Minoufiya University, Shebin El-Kom, Egypt.

[24] Ahmed, S. K. (2015). Utilization of by-products of food industries in the production of snacks with high nutritional value and healthy safe " Ph. D. Thesis in Nutrition and Food Science, Faculty of Home Economics, Minoufiya University, Egypt.

[25] Shalaby, H. H. (2015). The effect of some food products mixed with plant parts on blood sugar levels of rats " Ph. D. Thesis in Nutrition and Food Science, Faculty of Home Economics, Minoufiya University, Egypt.

[26] Ahmed, A. S. (2016). Nutritional and technological studies on the effect of phytochemicals on obesity injuries and their related diseases by using experimental animals ". Ph. D. Thesis in Nutrition and Food Science, Faculty of Specific Education, Port Saied University, Port Saied, Egypt. 
[27] Manley, D. (2001). Biscuit, cracker and cookie recipes for the food industry. Cambridge: Woodhead Publishers.

[28] Singleton, V. and Rossi, J. (1965). Colorimetry of total phenolics with phosphomolybdic-phosphotungstic acid reagents. Am. J. Enol. Vitic., 16: 144-158.

[29] Litchenthaler, H. K. (1987). Chlorophylls and carotenoids: pigments of photosynthetic biomembranes. Methods in Enzymology, 148: 350-383.

[30] Asp, N. G.; Johnson, C. G.; Hallomer, H. and Siljestrom, H. (1983). Rapid enzymatic assay of insoluble dietary fiber. Journal of Agricultural and Food Chemistry, 31: 476-482.

[31] Marco, G. (1968). A rapid method for evaluation of antioxidants. J. Am. Oil Chem. Soc., 45: 594-598.

[32] Al-Saikhan, M.; Howard, L. and Miller, J. (1995). Antioxidant activity and total phenolics in different genotypes of potato (Solanum tuberosum, L.). J. Food Sci., 60(2): 341-343.

[33] Marinova, E.; Yanishlieva, N. and Kostova, I. (1994). Antioxidative action of the ethanolic extract and some hydroxycoumarins of Fraxinusornus bark. Food Chem., 51: 125-132.

[34] Mallett, J.; Cerrati, C.; Ucciani, E.; Gamisana, J. and Gruber, M (1994). Antioxidant activity of plant leaves in relation to their $\alpha$-tocopherol content. Jornal of Food Chem., 49: 61-65.

[35] Al-Weshahy, A. and Rao, V. (2012). Potato Peel as a Source of Important Phytochemical Antioxidant Nutraceuticals and Their Role in Human Health - A Review, Phytochemicals as Nutraceuticals - Global Approaches to Their Role in Nutrition and Health, Dr Venketeshwer Rao (Ed.), InTech, Rijeka, Croatia.

[36] Forsythe, W.; Chenoweth, W. and Bennink, M. (1976). The effect of various dietary fibers on serum cholesterol and laxation in the rat. Journal of Nutrition, 106: 26-32.

[37] Ballesteros, M.; Cabrera, R.; Saucedo, M.; Yepiz-Plascencia, G.; Ortega, M. and Valencia, M. (2001). Dietary fiber and lifestyle influence serum lipids in free living adult men. Journal of the American College of Nutrition, 20(6): 649-655.

[38] Gallaher, D. and Schneeman, B. (2001). Dietary fibre. In: Bowman AB, Russell MR, editors. Present knowledge in nutrition. Washington, DC, ILSI, 805.

[39] Camire, M.; Zhao, J. and Violette, D. (1993). In vitro binding of bile acids by extruded potato peels. Journal of Agricultural and Food Chemistry, 41(12): 2391-2394.

[40] Lazarov, K. and Werman, M. (1996). Hypocholesterlaemic effect of potato peels as a dietary fiber source. Journal of Medical Sciences Research, 24: 581-582.

[41] Bagger, M.; Andersen, O.; Nielsen, J. and Ryttig, K. (1996). Dietary fibres reduce blood pressure, serum total cholesterol and platelet aggregation in rats. British Journal of Nutrition, 75(3): 483-493.

[42] Erkkila, A. and Lichtenstein, A. (2006). Fiber and cardiovascular disease risk: how strong is the evidence? Journal of Cardiovascular Nursing, 21(1): 3-8.
[43] Alonso, A., Beunza, J., Bes-Rastrollo, M., Pajares, R., Martinez, M. (2006). Vegetable protein and fiber from cereal are inversely associated with the risk of hypertension in a Spanish cohort. Archives of Medical Research, 37(6): 778-786.

[44] Chandalia, M.; Garg, A.; Lutjohann, D.; von Bergmann, k.; Grundy, S. and Brinkley, L. (2000). Beneficial effect of high dietary fiber intake in patients with type 2 diabetes mellitus. The New England Journal of Medicine, 342: 1392-1398.

[45] Osuna-Martinez, U.; Reyes-Esparza, J. and Rodríguez-Fragoso, L. (2014). Cactus (Opuntia ficus indica): A Review on its Antioxidants Properties and Potential Pharmacological Use in Chronic Diseases. University of Sinaloa, Faculty of Biological and Chemical Sciences, Cualiacan, Mexico. Nat Prod Chem Res, 2: 153-161.

[46] Velioglu, Y. S.; Mazza, G.; Gao, L. and Oomah, B. D. (1998). Antioxidant activity and total phenolics in selected fruits, vegetables and grain products. J. Agric. Food Chem., 46 (10): 4113-4117.

[47] Onyeneho, N. and Hettiarachchy, S. (1993). Antioxidant activity, fatty acids and phenolic acids compositions of potato peels. Journal of the Science of Food and Agriculture, 62: 345-350.

[48] Ashoush, I. and Gadallah, E. (2011). Utilization of mango peels and seed kernels powders as sources of phytochemicals in Biscuit. World Journal of Dairy \& Food Sciences, 6 (1): 35-42.

[49] El-Sadany, M. (2001). The effect of dietary phytochemicals on the prevention of liver cancer initiation induced by some chemical carcinogenesis. M. Sc. Thesis, Fac. of Home Economics, Minufiya University, Shebin El-Kom, Egypt.

[50] Hegazy, W. (2009). Antioxidant activity of pomegranate (Punica granatum) fruits and its relationship with phenolic composition and processing technology. M. Sc. Thesis in Nutrition and Food Science, Faculty of Home Economics, Minoufiya University, Egypt.

[51] Ajila, C.; Leelavathi, K. and Prasada, J. (2008). Improvement of dietary fiber content and antioxidant properties in soft dough biscuit with the incorporation of mango peel powder. J. Cereal Sci., 48: 319-326.

[52] Broyart, B. (1998). Predicting colour kinetics during cracker backing. J Food Eng, 35(3): 351-368

[53] Brennan, J.; Norris, D.; Rodriguez, T.; Beddington, R. and Robertson, E. (2001). Nodal signaling in the epiblast patterns the early mouse embryo. Nature, 411: 965-969.

[54] Toma, R.; Orr, P.; Appolonia, B.; Dintzis, F. and Tabekhia, M. (1979). Physical and chemical properties of potato peel as a source of dietary fiber in bread. Journal of Food Science, 44(5): $1403-1407$.

[55] Orr, P.; Toma, R.; Munson, S. and D'Appolonia, B. (1982). Sensory evaluation of breads containing various levels of potato peel. American Potato Journal, 59(12): 605-612.

[56] Abdel-Magied, M. (1991). Effect of dietary fiber of potato peel on the rheological and organoleptic characteristics of biscuits. Egyptian Journal of Food Science, 19: 293-300. 